\title{
EVALUATION OF PHYTOCONSTITUENTS, AND ANTIMICROBIAL AND ANTIOXIDANT ACTIVITY OF JUGLANS REGIA FROM KASHMIR REGION
}

\author{
ISHFAQ KHAN, NEHA CHAUHAN, CHAUHAN PK, MOHD. AZHAR KHAN* \\ Department of Biotechnology, Faculty of Applied Sciences and Biotechnology, Shoolini University, Solan, Himachal Pradesh, India. \\ Email: mk.azhar1@gmail.com
}

Received: 02 August 2018, Revised and Accepted: 25 September 2018

\begin{abstract}
Objectives:Oral infections are among the major health problems with dental caries and periodontal diseases globally. In dentistry, the importance of plants has been acknowledged to cure diseases generated by several oral pathogens, one such medicinal plant is Juglans regia which is commonly known as walnut.

The main focus of the present study was to evaluate the antimicrobial efficacy (against oral pathogenic bacteria), free radical scavenging activity, and total phenolic and flavonoids content (TPC and TFC) of methanolic extract (ME) of J. regia obtained from Kashmir region.

Methods: The plant part was collected and its ME was prepared. ME was subjected to antibacterial activity against oral bacteria such as Staphylococcus aureus, Streptococcus mutans, and Pseudomonas aeruginosa. The free radical scavenging activity was determined using 2,2-diphenyl1-picrylhydrazylhydrate (DPPH) assay. TPC and TFC were also determined using a standard curve equation of gallic acid and quercetin. A standard curve using different concentrations of gallic acid and quercetin was drawn from which the concentration of phenols in the test sample was calculated and expressed in $\mathrm{mg} / \mathrm{g}$.
\end{abstract}

Results: The ME of J. regia was found effective against all the strains of microorganisms responsible for oral infection understudy. It was also observed that scavenging of DPPH increased with the increase in concentration for both standard ascorbic and methanolic bark extract of $J$. regia showing its antioxidant potential. The TPC and TFC of ME was found to be $43.35 \pm 0.079$ and $17.28 \pm 0.125$.

Conclusions: The results obtained from the study clearly indicate that the walnut bark from Kashmir region can be a good candidate for employment as an antibacterial against oral pathogens. J. regia bark was found to be a good source of healthy compounds such as phenolic and flavonoids, suggesting that its bark could be useful to prevent diseases in which free radicals are present.

Keywords: Antimicrobial, Antioxidant, Oral infections, Total phenolic content and total flavonoid content.

(C) 2019 The Authors. Published by Innovare Academic Sciences Pvt Ltd. This is an open access article under the CC BY license (http://creativecommons. org/licenses/by/4. 0/) DOI: http://dx.doi.org/10.22159/ajpcr.2019.v12i2.28800

\section{INTRODUCTION}

Medicinal plants act as best basic material and a great source of phytoconstituents that have infinite application in medicine. Plants with medicinal value are used to cure several diseases since ancient times. Medicinal plants getting familiarized in various countries because they exist in nature with fewer side effects. Juglans regia is also included in this category. J. regia is a big deciduous tree found mainly in Iran, Baluchistan, Himalayan regions of India, Armenia, and several temperate regions [1]. In India, Kashmir occupies the largest position in the total production of walnut. It is highly beneficial and common plant of Kashmir where it is known as Doon. People in this region use different parts of this tree to treat several diseases. Many bacteria possess resistance against various antibiotics and due to the high rate of chemical antibiotics side effects; plants with medicinal value can be included as alternatives to chemical antibiotics due to the presence of secondary metabolites. Phenolic compounds of the root and stem are thought to be beneficial for human health, limiting the threat of infection by minimizing the oxidative stress [2]. In addition to their anticarcinogenic activity, the walnut bark has antioxidant and metal chelating activity [3]. The bark of the walnut tree contains flavonoids, phenolic compounds, alkaloids, and steroids [4]. The bark from J. regia is used as a tooth cleaner. In dentistry, walnut stem bark is recognized treat infections initiated by oral pathogens. $>760$ species of bacteria are responsible for oral infection, of which $50 \%$ are unknown [5]. The worldwide requirement for alternative prevention, treatment choices, and products for oral infections that are harmless, efficient, and cost-effective comes from the elevation in disease occurrence usually in developing countries, rise in multidrug resistance by several pathogenic microorganisms to antibiotics and several drugs [6,7]. The World Health Organization in 2007 reported that community health expenditure specific to dental care was $5-10 \%$. Tooth decay and oral infection treatment are probably very expensive that people have to struggle with for a lifetime [8]. Natural plant products are used even to correct numerous oral infections. In Burkina Faso, West Africa $>62$ species of plants belong to 29 families documented to cure oral infections. It is supposed that a quarter of recommended medicine contains constituents taken from the plants in industrialized countries [9]. Despite the great progress in medical sciences, plants are still thought to be a vital source of different drugs in various countries around the globe. Dependability on herbs has to turn out to be vital due to adverse effects possessed by chemical drugs such as tooth discoloration, change in taste, and formation of resistant microbes restricted its use.

\section{METHODS}

Sample collection

The bacterial strains Streptococcus mutans (MTCC-890), Staphylococcus aureus (MTCC-737), and Pseudomonas aeruginosa (MTCC-741) were obtained from IMTECH, Chandigarh. The clinical strains of P. aeruginosa and $S$. aureus were obtained from Molecular and Immuno-Parasitology Research Laboratory of Shoolini University. These strains were cultured in broth (Nutrient broth) followed by incubation for $24 \mathrm{~h}$ at $37^{\circ} \mathrm{C}$. The 
bark of J. regia stem was collected in July from Kulgam district in Jammu and Kashmir.

\section{Plant material processing}

The plants collected were authenticated with farm receipt no. 048 and book no. 2915. The bark was surface sterilized with mercuric chloride and dried in shade for 14 days. The dried bark was then crushed into a powdered form and extracted with methanol for 2 days using orbital shaker method. The extracted material was separated using Whatman filter paper no.1, the methanol was evaporated in a water bath at temperature $<40^{\circ} \mathrm{C}$, and then, crude extract was kept in a refrigerator at $4^{\circ} \mathrm{C}$ for further use.

\section{Antibacterial activity}

The antibacterial property of plant extract was determined using well diffusion assay [10]. The 0.5 McFarland was used as a

Table 1: Inhibition zone of methanolic bark extracts of $\mathrm{J}$. regia on oral bacteria $(\mathrm{mm})$

\begin{tabular}{llll}
\hline Bacterial strains & $\begin{array}{l}\text { Inhibition } \\
\text { zone of ME }\end{array}$ & $\begin{array}{l}\text { Inhibition zone of } \\
\text { positive control }\end{array}$ & $\begin{array}{l}\text { Negative } \\
\text { control }\end{array}$ \\
\hline S. aureus (standard) & $16.3 \pm 0.3$ & $25 \pm 0$ & - \\
S. aureus (clinical) & $16.6 \pm 0.6$ & $26 \pm 0$ & - \\
P. aeruginosa (standard) & $17.4 \pm 0.9$ & $29 \pm 0$ & - \\
P. aeruginosa (clinical) & $17.9 \pm 0.4$ & $24 \pm 0$ & - \\
S. mutans (standard) & $17 \pm 0.0$ & $29 \pm 0$ & - \\
\hline
\end{tabular}

S. aureus: Staphylococcus aureus, P. aeruginosa: Pseudomonas aeruginosa,

S. mutans: Streptococcus mutans, J. regia: Juglans regia, -=No zone

Table 2: Preliminary phytochemical screening of methanolic bark extract of $J$. regia

\begin{tabular}{ll}
\hline Phytoconstituents & ME of J. regia \\
\hline Flavonoids & + \\
Phenols & + \\
Alkaloids & + \\
Terpenoids & + \\
Cardiac glycosides & + \\
Saponins & - \\
Amino acids & + \\
Carbohydrates & + \\
Tannins & - \\
Fixed oils and fats & - \\
Steroids & + \\
Phlobatannins &
\end{tabular}

+: Indicates the presence of phytoconstituents. -: Indicates the absence

of phytoconstituents in ME of Juglans regia. ME: Methanolic extract,

J. regia: Juglans regia

Table 3: TPC and TFC of methanolic bark extract of J. regia

\begin{tabular}{lll}
\hline Sample & TPC & TFC \\
\hline J. regia & $43.35 \pm 0.079 \mathrm{mg} / \mathrm{g}$ & $17.28 \pm 0.125 \mathrm{mg} / \mathrm{g}$ \\
\hline J. regia: Juglans regia, & TPC: Total phenolic content, TFC: Total flavonoids content
\end{tabular}

standard $\left(1.5 \times 10^{8}\right.$ cells $\left./ \mathrm{ml}\right)$ to adjust the turbidity of subcultured microorganisms. Mueller-Hinton agar plates were prepared and test microorganisms were seeded on the plates by spread plate process. After incubating for $30 \mathrm{~min}$ at room temperature, wells were punched with the help of borer. The dried extract was mixed with dimethyl sulfoxide (DMSO) and $50 \mu$ lof the extract was added to the wells. The standard was prepared for an antibiotic, chloramphenicol (HiMedia) as a positive control. DMSO was also added in a well as negative control to confirm that DMSO does not possess any antibacterial activity. After $24 \mathrm{~h}$ of incubation, the inhibition zone was measured and compared with an inhibition zone of the standard antibiotic used.

\section{Phytochemical screening}

Methanolic extract (ME) was screened for the detection of phytoconstituents. Results of phytoconstituents screening are summarized in Table 1. Phytochemical screening was performed in the test tubes. The observations (Table 1) confirmed the presence of phytocomponents such as phenols, flavonoids, terpenoids, tannins, glycosides, phlobatannins, and cardiac glycosides.

\section{Total phenolic estimation}

In alkaline medium, the reaction of phenols with the phosphomolybdic acid of Folin-Ciocalteu reagent takes place and forms blue-colored complexes that are determined spectroscopically [11]. The overall phenols present in the sample were confirmed by a method involving Folin-Ciocalteu reagent (oxidizing agent) and gallic acid (standard). A standard gallic acid solution with a concentration of solution as $1 \mathrm{mg} / \mathrm{ml}$ or $1000 \mu \mathrm{g} / \mathrm{ml}$ was prepared. Serial dilution was performed to get different concentrations of reference gallic acid. In another test tube, $0.1 \mathrm{ml}$ of the sample was added. Then, $1.5 \mathrm{ml}$ of Folin-Ciocalteu (1:1 ratio) reagent and $1.2 \mathrm{ml} \mathrm{Na}_{2} \mathrm{CO}_{3}(7.5 \%)$ was transferred. In each test tube followed by incubation at $25^{\circ} \mathrm{C}$ for $20 \mathrm{~min}$ and finally absorbance was taken at $765 \mathrm{~nm}$. Using different concentrations, a standard curve was drawn from which the amount of phenols in the sample was calculated and expressed as $\mathrm{mg} / \mathrm{g}$

\section{Total flavonoid content (TFC) estimation}

The $\mathrm{AlCl}_{3}$ colorimetric method was performed to know the concentration of flavonoids in the sample [12]. In this method $\left(\mathrm{AlCl}_{3}\right.$ colorimetric method), acid stable compounds are formed by $\mathrm{AlCl}_{3}$ with C-4 keto and C-5 hydroxyl groups of flavonoids. Studies have described quercetin to be proper standard to determine the concentration of flavonoids in a sample extract. Hence, quercetin solution with different concentrations was taken to create the calibration curve. $10 \mathrm{mg}$ of quercetin was mixed in $10 \mathrm{ml}$ of methanol and then diluted to different concentrations of 20,40 , 60,80 , and $100 \mu \mathrm{g}$ using methanol. The assay was performed using $0.1 \mathrm{ml}$ of extract from stock solution $(\mathrm{mg} / \mathrm{ml}), 0.2 \mathrm{ml}$ of $5 \%$ sodium nitrate was added in each test tube. After $5 \mathrm{~min}, 0.2 \mathrm{ml}$ of $10 \% \mathrm{AlCl}_{3}$ was added to the mixture, and finally, after $6 \mathrm{~min}, 2 \mathrm{ml}$ of $1 \mathrm{M} \mathrm{NaOH}$ was added. Absorbance was taken at $510 \mathrm{~nm}$. A standard curve with several concentrations of quercetin was drawn on the basis, of which concentration of phenols in the sample was calculated and expressed as $\mathrm{mg} / \mathrm{g}$.

\section{Free radical scavenging activity}

The free radical scavenging property of extract was calculated using 2,2-diphenyl-1-picrylhydrazylhydrate (DPPH) assay [13]. Using

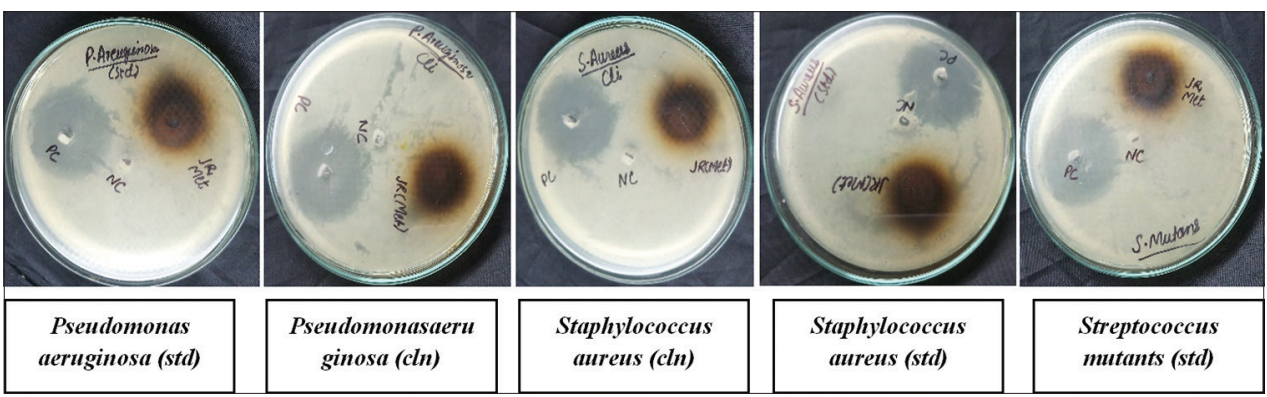

Fig. 1: Inhibition zones of methanolic extracts of Juglans regia against oral bacteria 
methanol, $0.004 \% \mathrm{w} / \mathrm{v}$ of DPPH solution was prepared using methanol. Stock solution $(1 \mathrm{mg} / \mathrm{ml})$ of the sample and ascorbic acid were made using methanol. Several concentrations of sample and ascorbic acid were prepared in test tubes and $2.5 \mathrm{ml} \mathrm{DPPH}$ was added and tubes were kept in dark for $30 \mathrm{~min}$. After incubation, the absorbance was taken at $517 \mathrm{~nm}$ using a spectrophotometer. A control sample was prepared using methanol and DPPH. Methanol was taken as a blank.

$$
\% \text { of scavenging }=\frac{\begin{array}{l}
\text { Absorbance of control }- \\
\text { Absorbance of sample }
\end{array}}{\text { Absorbance of control }} \times 100
$$

\section{Statistical analysis}

All the results data have been expressed in the form of mean \pm standard deviation.

\section{RESULTS}

\section{Antibacterial activity}

Antibacterial activity of ME of J. regia was investigated and the results revealed different inhibition zones as shown in Table 1 and Fig. 1. The result showed that the ME was found to be potential antibacterial agents against the oral pathogenic bacteria which are responsible for different types of oral infections.

\section{Phytochemical screening}

The result revealed that MEs of $J$. regia contain flavonoids, phenols, terpenoids, cardiac glycosides, saponins, and tannins, whereas carbohydrates, alkaloids, fats, and steroids were found absent. Preliminary phytochemical screening results were described in Table 2.

\section{Total phenols and flavonoids estimation}

Using standard curve equation of gallic acid and quercetin equivalents, the total phenolic content (TPC) and TFC of methanolic bark extract of J. regia was calculated and was found to be $43.35 \pm 0.079 \mathrm{mg} / \mathrm{g}$ and $17.28 \pm 0.125 \mathrm{mg} / \mathrm{g}$, respectively (Figs. 2 and 3 , Table 3 ).

\section{Free radical scavenging activity}

The free radical scavenging activity of methanolic bark extract of J. regia was evaluated using DPPH. It was seen that the scavenging activity of DPPH increased with the increase in concentration for both standard ascorbic acid and methanolic bark extract of J. regia interestingly (Fig. 4).

\section{DISCUSSION}

The main agent responsible for gum inflammation and dental cavities is a dental plaque. Some people avoid the use of chemical mouth rinse due to side effects such as tooth discoloration, change in taste, and formation of resistant microbes [14]. Hence, currently, the researchers are looking for medicinal plants to eliminate different kinds of infections. The current study showed that J. regia has a capability to serve as a potential antibacterial agent and thus can be used in oral hygiene products. According to our study, we indicated that ME of J. regia was effective in inhibiting the three bacteria $S$. mutans, $S$. aureus, and $P$ aeruginosa. The inhibition zones are shown in Table 1 and Fig. 1. Mohammed, 2012, reported the inhibition effect of ME of $J$. regia bark against $S$. aureus, S. mutans, and P. aeruginosa [15] which were less effective as compared to our methanolic bark extract. The antibacterial property possessed by the plant is due to the presence of phenolic compounds, flavonoids, tannins, and terpenoids [16]. Phenols are very essential plant components due to their capability to scavenge free radicals as they contain hydroxyl group groups in their structure; therefore, plant phenols may contribute directly to their antioxidant potential. Some studies were performed to know the amount of phenolics present in the bark extract of J. regia. Asha et al., 2010, reported that the presence of total phenols and flavonoids in bark extract of J. regia, the TPC and TFC, was $20.32 \mathrm{mg} / \mathrm{g}$ and $11.48 \mathrm{mg} / \mathrm{g}$, respectively, of dry weight [17]. On the other hand, Ogunmoyole et al., 2011, reported the values of TPC and TFC ranging from $35.22 \pm 0.75 \mathrm{mg} / \mathrm{g}$ to $20.2 \pm 0.12 \mathrm{mg} / \mathrm{g}$ [18]. Interestingly, the result indicates higher phenolic and flavonoid content in our sample too

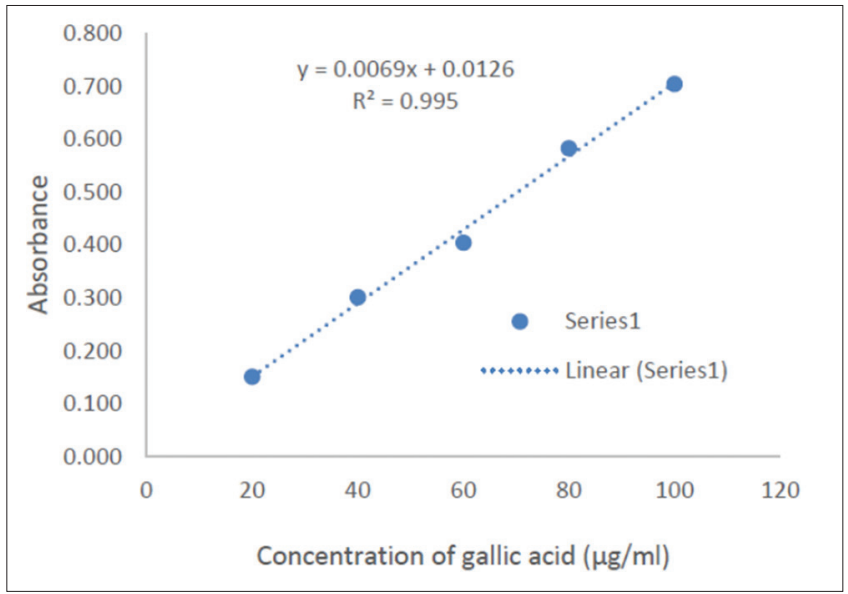

Fig. 2: Graphical representation of the standard curve of gallic acid

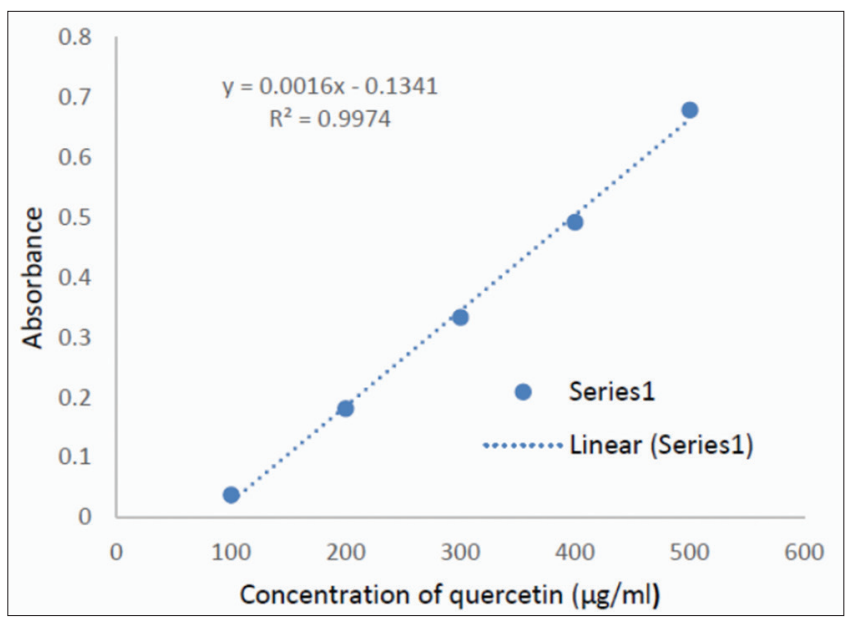

Fig. 3: Graphical representation of the standard curve of quercetin

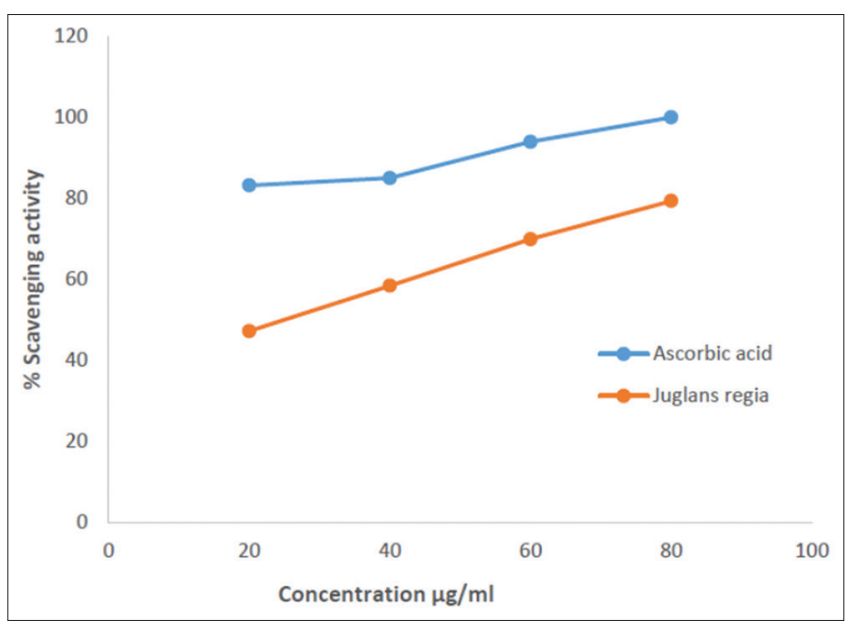

Fig. 4: DPPH scavenging activity of standard ascorbic acid and methanolic bark extract of Juglans regia

$(43.35 \pm 0.079 \mathrm{mg} / \mathrm{g}$ and $17.28 \pm 0.125 \mathrm{mg} / \mathrm{g})$. The difference may exist due to environmental factors, genetic factors, and date of sampling.

Scavenging process of free radical is an important mechanism in which antioxidant components reduce the oxidation of lipid. DPPH which acts as free radical has been currently used for the estimation of radical scavenging activity of different compounds. The free radical 
DPPH which dissolves in methanol has purple color and defined absorbance at $517 \mathrm{~nm}$. When antioxidant donates protons to DPPH, the purple color of the solution changes to yellow color with the decrease of absorbance [19]. The absorbance is inversely proportional to free radical scavenging activity. The scavenging activity of $J$. regia bark extract was found to be greater at a low concentration ranging from 20 to $80 \mu \mathrm{g} / \mathrm{ml}$ (47.16-79.31\%) while Kshitij et al, 2012, have reported at higher concentration of $50-500 \mu \mathrm{g} / \mathrm{ml}(20-80 \%)$.

\section{CONCLUSIONS}

The results obtained in the study clearly show that J. regia bark may be considered a good candidate for employment as an effective antimicrobial agent against oral bacteria which can cause many oral diseases. To elevate oral sanitation, medicinal plant-based mouthwash can be used as a mediator and acts as a part of efficient home care medication. J. regia bark may also be included as a good source of healthy compounds such as phenols and flavonoids, suggesting that it could be useful in the prevention of diseases in which free radicals are present.

\section{ACKNOWLEDGMENT}

The authors sincerely thank Shoolini University, Solan, Himachal Pradesh, for providing the necessary facilities to carry out this research work.

\section{CONFLICTS OF INTEREST}

The authors declare that they no conflicts of interest.

\section{REFERENCES}

1. Chopra RN, Nayar SL. Glossary of Indian Medicinal Plants. New Delhi: Council of Scientific and Industrial Research; 1956.

2. Silva BM, Andrade PB, Valentão P, Ferreres F, Seabra RM, Ferreira MA, et al. Quince (Cydonia oblonga Miller) fruit (pulp, peel, and seed) and jam: Antioxidant activity. J Agric Food Chem 2004;52:4705-12.

3. Middleton E. Effect of plant flavonoids on immune and inflammatory cell function. In: Flavonoids in the Living System. Boston, MA: Springer; 1998. p. 175-82.

4. Deshpande RR, Kale AA, Ruikar AD, Panvalkar PS, Kulkarni AA, Deshpande NR, et al. Antimicrobial activity of different extracts of Juglans regia L. against oral microflora. Int J Pharm Pharm Sci
2011;3:200-1

5. Jenkinson HF, Lamont RJ. Oral microbial communities in sickness and in health. Trends Microbiol 2005;13:589-95.

6. Tichy J, Novak J. Extraction, assay, and analysis of antimicrobials from plants with activity against dental pathogens (Streptococcus sp.) J Altern Complement Med 1998;4:39-45.

7. Raj TI, Kumar PU, Rathee R, Dubey K. Screening of some medicinal plants for their antimicrobial activities. Int J Pharm Pharm Sci 2016;8:202-6

8. Loesche WJ. Role of Streptococcus mutans in human dental decay. Microbiol Rev 1986;50:353-80.

9. Runyoro DK, Ngassapa OD, Matee MI, Joseph CC, Moshi MJ.Medicinal plants used by Tanzanian traditional healers in the management of Candida infections. J Ethnopharmacol 2006;106:158-65.

10. Bauer AW, Kirby WM, Sherris JC, Turck M. Antibiotic susceptibility testing by a standardized single disk method. Am J Clin Pathol 1966;45:493-6.

11. Singleton VL, Orthofer R, Lamuela-Raventós RM. Analysis of total phenols and other oxidation substrates and antioxidants by means of folin-ciocalteu reagent. In: Methods in Enzymol. Vol. 299. San Diego, CA: Academic press; 1999. p. 152-78.

12. Atanassova M, Georgieva S, Ivancheva $\mathrm{K}$. Total phenolic and total flavonoid contents, antioxidant capacity and biological contaminants in medicinal herbs. J Univ Chem Technol Metall 2011;46:81-8.

13. Braca A, Tommasi ND, Bari LD, Pizza C, Politi M, Morelli I. Antioxidant principles from Bauhinia terapotensis. J Nat Prod 2001;64:892-5.

14. Yadav M, Chatterji S, Gupta SK, Watal G. Preliminary phytochemical screening of six medicinal plants used in traditional medicine. Int $\mathrm{J}$ Pharm Pharm Sci 2014;6:539.

15. Mohammed NA. Comparison of antimicrobial activities of methanol extracts of Juglans regia against Staphylococcus aureus, and Streptococcus mutans with ciprofloxacin: In Vitro. Almustansiriyah J Sci 2012;23:1-6.

16. Sharma PC, Yelne MB, Dennis TJ, ediotors. "Bhunimba (Andrographics paniculata)," in Data Base on Medicinal Plants used in Ayurveda. Vol. 4. New Delhi, India: Central Council for Research in Ayurveda and Siddha; 2002. p. 34-60.

17. Asha K, Sucheta G, Kavita M, Nirmala D, Jyoti S. Quantification of phenolics and flavonoids by spectrophotometer from-Juglans regia. Inte J Pharma Bio Sci 2010;1:1-4.

18. Ogunmoyole T, Kade IJ, Korodele B. In vitro antioxidant properties of aqueous and ethanolic extracts of walnut (Juglans regia). J Med Plants Res 2011;5:6839-48.

19. Sannigrahi S, Mazumder UK, Pal D, Mishra SL. Hepatoprotective potential of methanol extract of Clerodendrum infortunatum L. against CCl4 induced hepatotoxicity in rats. Indian J Exp Bio 2009;5:394-9. 